Rev. Saúde públ., S. Paulo

7: 123-38, 1973.

\title{
SITUAÇÃO DA ASSISTÊNCIA MÉDICO-SANITÁRIA E HOSPITALAR NO ESTADO DO CEARÁ, BRASIL
}

João YUNES *

RSPU-B/166

Yunes, J. - Situação da assistência médico-sanitária e hospitalar no Estado do Ceará, Brasil. Rev. Saúde públ., S. Paulo, 7:123-38, 1973.

RESUmo: Foi examinada a situação da assistência médico-sanitária e hospitalar no Estado do Ceará (Brasil), através da análise da oferta dos serviços oficiais de saúde pública, da assistência hospitalar e para-hospitalar, bem como dos recursos humanos existentes. Este Estado conta com 141 municipios e com uma população aproximada de 4.000 .000 de habitantes. Os serviços oficiais de Saúde Pública são de responsabilidade do poder público Estadual em 59,6\% das unidades sanitarias, o poder puiblico Federal participa em 26,9\% e o Municipal em 13,5\%. O padrấo quantitativo observado foi considerado satisfatorio, pois encontrou-se em média uma unidade sanitária para cada 23.002 habitantes, aproximando-se do recomendado de um para cada 50.000 habitantes. A avaliação qualitativa, medida indiretamente através dos recursos laboratoriais e humanos existentes, apresentou-se deficitária uma vez que somente 16,7\% das unidades sanitárias contam com laboratorio e $12,3 \%$ não possuem médico, sendo que $21,7 \%$ (39) dos centros de saúde encontram-se fechados por carência deste tipo de profissional. Dos 141 municípios que compõem o Estado, 31 (22,4\%) não possuem unidade sanitäria e 25 (17,71\%) não contam com nenhum recurso de saúde. No primeiro caso a população teoricamente descoberta de assistência médica é de 378.449 habitantes e no segundo é de 232.900 habitantes. Dos 103 hospitais existen. tes no Estado $77,7 \%$ é de responsabilidade do setor privado e $25 \%$ encontram-se concentrados na Capital do Estado. $O$ padrão quantitativo encontrado de 1,84 leitos/1000 habitantes (7047 leitos), é baixo quando comparado com a média brasileira de 3,6 leitos, quando o teoricamente recomendado é em média de 4,5. Do total de leitos, 1,10/1000 são considerados gerais e 0,74/1000 especializados (tuberculose, lepra e psiquiatria). O padrão qualitativo de atendimento hospitalar é comprometido, uma vez que somente $22,3 \%$ dos estabelecimentos contam com laboratórios, $31,1 \%$ com aparelhos de Raios $X$ e $11,6 \%$ com eletrocardiografia. A maior carência destes recursos encontram-se no Interior do Estado. Mais de 50\% dos hospitais não contam com profissionais de saúde tais como enfermagem, nutricionistas, assistente social e técnicos. Dos 141 municipios, 62,7\% (89) não possuem nenhum hospital, fazendo com que cerca de 1.300.000 habitantes estejam teoricamente descobertos da assistência hospitalar. Em relação às 86 unidades para-hospitalares existentes, embora a carência de dados seja maior, a situação é bastante semelhante à da assistência hospitalar. No Estado existem 1.207 médicos que proporcionam um padrão somente de 0,3/1000 habitantes quando o teoricamente recomendado é em média de 1/1000 habitantes. Além do número ser insuficiente há má distribuição, pois $77,7 \%$ destes profissionais estão con-

* Do Centro de Estudos de Dinâmica Populacional da Faculdade de Saúde Pública da USP - Av. Dr. Arnaldo, 715 - São Paulo, SP - Brasil. Da Disciplina de Pediatria Social da Faculcade de Medicina da USP - Av. Dr. Arnaldo, 455 - São Paulo, SP - Brasil. Da Divisão de Epidemiologia da Secretaria de Saúde do Estado de São Paulo. 
YUNES, J. - Situação da assistência médico-sanitária e hospitalar no Estado do Ceará, Brasil. Rev. Saúde públ., S. Paulo, 7: 123-38, 1973.

centrados na Capital do Estado (1,1/1000 habitantes). Somente 45,4\% dos municípios contam com médicos residentes. $E m$ relação a dentistas encontra-se um padrão quantitativo baixo de 0,28 profissionais por 2000 habitantes quando o geralmente aceito é de 1/2000 habitantes. Em relação ao pessoal paramédico, predominam, nos serviços oficiais de Saúde Pública, as atendentes e nos hospitais, como já foi mencionado mais de 50\% não possue pessoal qualificado.

Unitermos: Assistência médico-sanitária (Ceará, Brasil)*; Assistência hospitalar (Ceará, Brasil)*; Saúde pública (serviços)*.

$$
1 \text { - I N T R O D U Ç A O }
$$

A análise da situação da assistência médica no Estado do Ceará será avaliada através do estudo da oferta dos serviços oficiais de saúde pública, da assistência hospitalar e para-hospitalar, bem como, dos recursos humanos existentes. Este estudo integrou o Plano do Governo do Estado do Ceará em 1971 e tem como objetivo o conhecimento da situação existente a fim de permitir uma programação mais adequada do setor saúde, contribuindo para o plano de desenvolvimento integrado da área de estudo.

O Estado do Ceará conta com $141 \mathrm{mu}$ nicípios perfazendo uma população aproximada de 4.000.000 de habitantes.

As informações utilizadas referem-se ao último ano em que o dado foi disponível $e$ as principais fontes dos dados brutos foram do Departamento Nacional de Endemias Rurais (DNERu), Departamento Estadual de Estatística (DEE), Prefeitura Municipal de Fortaleza, Centro Médico Cearense e Conselho Regional de Odontologia, que uma vez tabulados permitiu a análise dos resultados que se seguem.

$$
2 \text { - RESULTADOS }
$$

\section{1 - Assistência Médico-Sanitária}

Os serviços oficiais de saúde pública prestam assistência médica geral e especializada. A assistência médica geral no
Estado do Ceará é prestada por diferentes tipos de unidades sanitárias que, de acordo com os programas desenvolvidos, obedecem terminologia específica segundo critérios da Secretaria da Saúde.

Centro de Saúde: é uma unidade sanitária que presta atendimento completo integrado por serviços especializados, localizado na capital do Estado.

Posto de Saúde: é uma unidade sanitária que presta assistência médica geral sem serviços especializados.

Sub-Posto de Saúde: é uma unidade sanitária que funciona por convênio com outras entidades.

Unidades Rudimentares: são unidades simples de atendimento geral localizadas no interior do Estado.

A assistência médica especializada é representada pelos programas de tuberculose e lepra e funciona em geral integrada a uma unidade sanitária de responsabilidade Estadual ou Federal (Departamento Nacional de Endemias Rurais e Fundação SESP).

A assistência médico-sanitária prestada pelos serviços oficiais de saúde pública no Estado do Ceará tem participação do poder público Estađual, Federal e Municipal. O poder público Estadual é o que mais participa neste tipo de atendimento, pois $59,6 \%$ das unidades sanitárias do 
YUNES, J. - Situação da assistência médico-sanitária e hospitalar no Estado do Ceará, Brasil. Rev. Saúde públ., S. Paulo, 7: 123-38, 1973.

Estado são de sua responsabilidade. $O$ poder público Federal participa em $26,9 \%$ e o Municipal em $13,5 \%$. A participação destas instituições na Capital do Estado (Fortaleza) e no Interior encontra-se na Tabela 1.

T A B E L A 1

Distribuição dos Serviços Oficiais de Saúde Pública, segundo a Entidade Mantenedora (Estado do Ceará)

1968

\begin{tabular}{|c|c|c|c|c|c|c|c|c|c|}
\hline \multirow{2}{*}{\multicolumn{2}{|c|}{ Localidade }} & \multicolumn{2}{|c|}{ TOTAL } & \multicolumn{2}{|c|}{ Federal } & \multicolumn{2}{|c|}{ Estadual } & \multicolumn{2}{|c|}{ Municipal } \\
\hline & & N.o & $\%$ & N.o & $\%$ & N.O & $\%$ & N. ${ }^{\circ}$ & $\%$ \\
\hline Fortaleza & $\ldots$ & 10 & 100,0 & $1^{*}$ & 10,0 & 8 & 80,0 & $1 * *$ & 10,0 \\
\hline Interior & $\ldots \ldots \ldots \ldots$ & 146 & 100,0 & 41 & 28,1 & 85 & 58,2 & 20 & 13,7 \\
\hline Estado & ........... & 156 & 100,0 & 42 & 26,9 & 93 & 59,6 & 21 & 13,5 \\
\hline
\end{tabular}

Fonte: DEE

* DNERU

* Unidade Médica Volante.

T A B E L A 2

Unidades de saúde pública e populaçãço servida por regióes - (Estado do Ceará)

1970

\begin{tabular}{c|c|c|c|c}
\hline Regióes & $\begin{array}{c}\text { N.0 } \\
\text { Municipios }\end{array}$ & $\begin{array}{c}\text { Unid. de Saú- } \\
\text { de Pública }\end{array}$ & População & $\begin{array}{c}\text { N.o de habitantes } \\
\text { por unidade }\end{array}$ \\
\hline \hline $1 .^{\mathrm{a}}$ & 27 & 40 & 1.520 .252 & 38.006 \\
$2 .^{\mathrm{a}}$ & 33 & 41 & 628.731 & 15.335 \\
$3 .^{\mathrm{a}}$ & 10 & 13 & 358.005 & 27.539 \\
$4 .^{\mathrm{a}}$ & 16 & 22 & 324.708 & 14.759 \\
$5 .^{\mathrm{a}}$ & 14 & 17 & 399.157 & 23.480 \\
$6 .^{\mathrm{a}}$ & 15 & 18 & 336.784 & 18.710 \\
$7 .{ }^{\mathrm{a}}$ & 26 & 28 & 549.773 & 19.635 \\
TOTAL & 141 & 179 & 4.117 .410 & 23.002 \\
\hline
\end{tabular}

Fonte: Serviço de Saúde do Interior (DES) - DNERu - Fundação Serviço Especial de Saúde Pública (FSESP) - Instituto Brasileiro de Geografia e Estatística (IBGE) 
YUNES, J. - Situação da assistência médico-sanitária e hospitalar no Estado do Ceará, Brasil. Rev. Saúde públ., S. Paulo, 7: 123-38, 1973.

Para um total de 141 municípios que compõem o Estado do Ceará, existem 179 unidades de Saúde Pública com um padrão quantitativo de uma unidade sanitária para cada 23.002 habitantes (Tabela 2).

- Estado do Ceará, de acordo com critério adotado pela Secretaria da Saúde, está dividido em 7 Regiões. O número de habitantes por unidade sanitária variou de 14.759 (4. ${ }^{a}$ Regiáo) para 38.006 (1. Região). Pode-se considerar que os padrões quantitativos atuais são razoáveis, aproximando-se do recomendado que é de um para 50.000 habitantes em média. Entretanto, há que ressalvar que esse é apenas um entre os critérios adotados para se avaliar o padrão de atendimento. A avaliação mais precisa demandaria a análise de outros fatores, tais como, densidade demográfica, vias de acesso, facilidade de transporte e distribuição da população por classe de ren- da, elementos fundamentais na apreciação do padrão existente. Todavia, dada a dificuldade de se obter essas informações, somente foi utilizado o padrão quantitativo global.

A avaliação qualitativa torna-se ainda mais precária, pois os dados necessários para a sua realização são de difícil obtenção. Far-se-á, no entanto, essa avaliação de forma indireta através dos recursos laboratoriais e humanos existentes.

Das 179 unidades sanitárias existentes de responsabilidade do poder público, somente $30(16,7 \%)$ contam com laboratório. A proporção de unidades equipadas que contam com recursos para análises clínicas é de somente $13,4 \%$, exames parasitológicos $(13,4 \%)$, hematológicos $(8,4 \%)$, sorológico $(6,1 \%)$, bacteriológico $(5,6 \%)$ e anátomo-patológico $(1,1 \%)$, (Tabela 3).

T A B E L A 3

Laboratórtos equipados nos estabelecimentos oficiais de saúde pública (Estado do Ceará) 1968

\begin{tabular}{l|c|c|c|c}
\hline \multicolumn{1}{c|}{ Laboratórios } & Fortaleza & Interior & Estado & $\begin{array}{c}\text { \% de Unidades } \\
\text { Equipadas }\end{array}$ \\
\hline Análises Clínicas & 3 & 21 & 24 & 13,4 \\
Bacteriologia & 3 & 7 & 10 & 5,6 \\
Parasitologia & 3 & 21 & 24 & 13,4 \\
Hematologia & 2 & 13 & 15 & 8,4 \\
Sorologia & 1 & 10 & 11 & 6,1 \\
Anatomia Patológica & - & 2 & 2 & 1,1 \\
\hline
\end{tabular}

Fonte: DEE.

A carência desses serviços que complementam o diagnóstico do paciente, comprometem de muito a qualidade do atendimento e o prognóstico de cura.

Quanto à disponibilidade de pessoal médico, consta-se que das unidades sani- 
YUNES, J. - Situação da assistência médico-sanitária e hospitalar no Estado do Ceará, Brasil. Rev. Saúde pübl., S. Paulo, 7: 123-38, 1973.

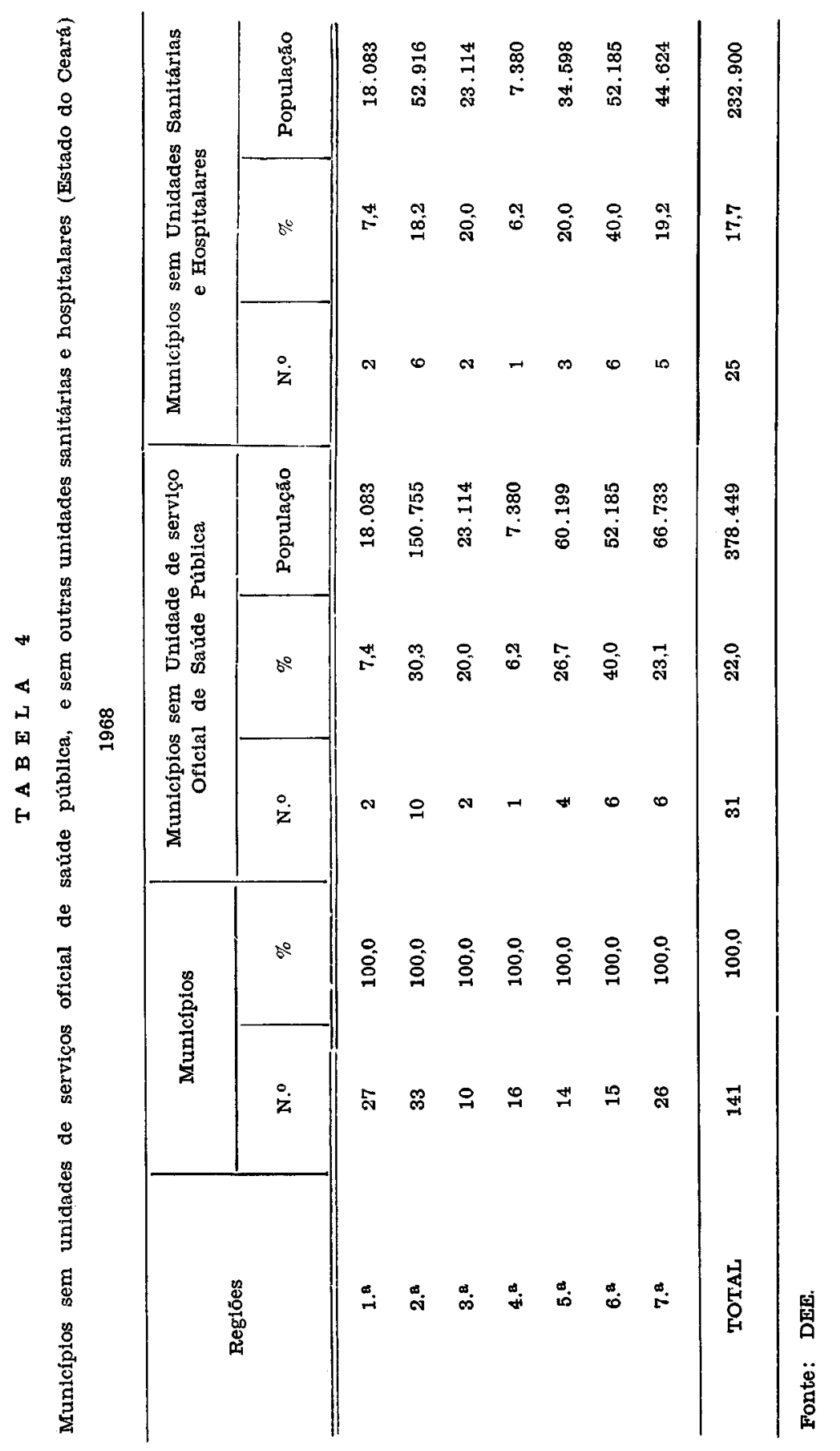


YUNES, J. - Situação da assistência médico-sanitária e hospitalar no Estado do Ceará, Brasil. Rev. Saúde públ., S. Paulo, 7: 123-38, 1973.

tárias do Estado, 12,3\% não possuem médicos. Esta carência é maior para a 1. Região onde esta proporção alcança a taxa de 27,5\%, seguindo-se da $3 .^{\text {a }}$ Região com 15,4\%, 6. ${ }^{a}$ Região (11,1\%), 2. ${ }^{a}$ Região $(9,8 \%)$ e $7 .^{a}$ Região $(7,1 \%)$. Esta situação torna-se mais caótica quando se constata que 39 unidades sanitárias, isto é, $21,7 \%$ dos totais existentes encontram-se fechadas por carência de pessoal médico. Muitas unidades sanitárias estão sendo atendidas por médicos que residem em outras localidades. Esta situação impede qualquer nível satisfatório de atendimento exigido, comprometendo tanto o padrão quantitativo como qualitativo.

Constata-se por outro lado que os aparelhos existentes nas unidades sanitárias são bastante obsoletos e que há deficiên. cia quase que absoluta no suprimento de medicamentos destas unidades.

Esta situação impede qualquer nível satisfatório de atendimento desejável comprometendo seriamente tanto o padrão quantitativo como qualitativo.

O diagnóstico da situação torna-se ainda mais comprometido quando se constata que dos 141 municípios que compõem o Estado do Ceará, 31 (22,0\%) não possuem unidade sanitária sob responsabilidade do poder público e 25 $(17,7 \%)$ não possuem nenhuma unidade sanitária e nem hospitalar. No primeiro caso a população teoricamente descoberta de assistência médica sob responsabilidade do poder público é de 378.449 habitantes, (9,9\% da população do Estado), e no segundo caso a população descoberta de qualquer tipo de assistência médica é de 232.900 habitantes $(6,1 \%)$ da população do Estado. Ao se analisar esta situação por Região, a que se encontra em pior situação, de acordo com o ta- manho da população teoricamente descoberta, é a $2 .^{2}$ seguindo-se da 7. ${ }^{\mathrm{a}}, 5 .^{\mathrm{a}}, 6 .^{\mathrm{a}}$, 3. ${ }^{\mathrm{a}}$ 1. ${ }^{\mathrm{a}}$ e 4." (Tabela 4 ).

\section{2 - Assistência Hospitalar e Para-Hospitalar}

$\mathrm{Na}$ análise da rede hospitalar e para-hospitalar (ambulatórios e pronto-socorros isolados) classificaram-se os estabelecimentos de acordo com a entidade mantenedora e finalidade, isto é, gratuitos e não gratuitos.

\subsection{1 - Rede Hospitalar}

A rede hospitalar compunha-se em 1968, de acordo com a Tabela 5, de 103 estabelecimentos estando sob a responsabilidade de entidades privadas, 77,7\% dos hospitais, $8,7 \%$ é de responsabilidade da esfera Estadual, 7,8\% da Federal, 4,8\% da Municipal e $1,0 \%$ da Para-estatal. Constata-se, portanto, que a esfera pública participa somente com $22,3 \%$ (23 hospitais) do total de hospitais existentes.

Cerca de $25 \%$ dos hospitais existentes encontram-se concentrados na capital do Estado. Os 103 estabelecimentos hospitalares são responsáveis pela existência de 7047 leitos (Tabela 6) que correspondem a 1,84 leitos/1000 habitantes. Do total de leitos, 4216 são do tipo geral $(1,10$ leitos/1000 habitantes) e 1506 especializados, isto é, destinados à tuberculose, lepra e psiquiatria e neurologia (0,74 leitos/1000 habitantes). O padrão quantitativo encontrado é baixissimo quando comparado com a média brasileira que é de 3,6 leitos/1000 habitantes* e com o padrão recomendado que é de 4,5 leitos gerais/1000 habitantes e 3,0 leitos especializados em média por mil habitantes.

- Anuário Estatístico do Brasil. (IBCE) 1971, p. 549. 
YUNES, J. - Situaçâo da assistência médico-sanitária e hospitalar no Estado do Ceará Brasil. Rev. Saúde públ., S. Paulo, 7: 123-38, 1973.

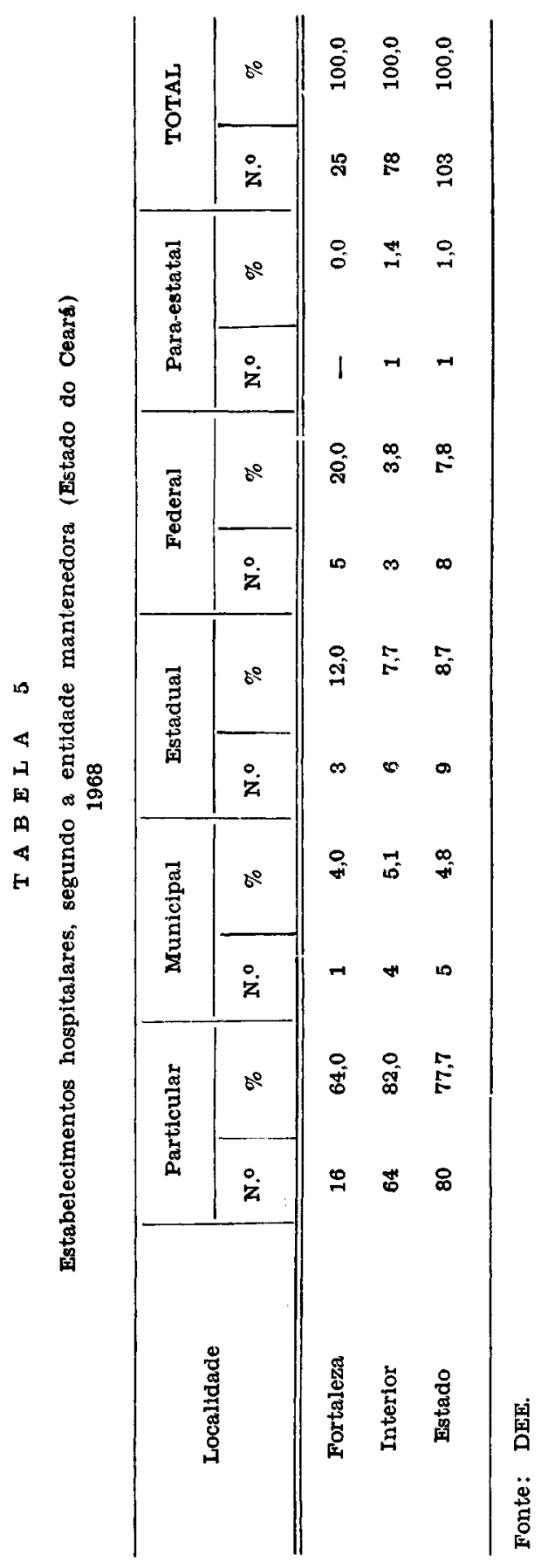


YUNES, J, - Situação da assistência médico-sanitária e hospitalar no Estado do Ceará, Brasil. Rev. Saúde públ., S. Paulo, 7: 123-38, 1973.

De 1964 a 1968 o coeficiente de leitos por mil habitantes evoluiu de 1,60 para 1,84. Este aumento como foi discreto não permitiu atingir a proporção de leitos necessários (Tabela 6).

T A B E L A 6

Evolução do coeficiente de leitos por habitantes (Estado do Ceará)

$1964-1968$

\begin{tabular}{|c|c|c|c|c|}
\hline \multirow{2}{*}{ Discriminação } & \multicolumn{2}{|c|}{1964} & \multicolumn{2}{|c|}{1968} \\
\hline & Número & $\begin{array}{l}\text { Leitos/1000 } \\
\text { Habitantes }\end{array}$ & Número & $\begin{array}{l}\text { Leitos } / 1000 \\
\text { Habitantes }\end{array}$ \\
\hline Leitos gerais & 3.206 & 0,90 & 4.216 & 1,10 \\
\hline Leitos especializados & 2.471 & 0,70 & 2.831 & 0,74 \\
\hline Tuberculose & 580 & 0,16 & 643 & 0,17 \\
\hline Lepra & 693 & 0,20 & 682 & 0,18 \\
\hline Psiquiatria e neurologia & 1.198 & 0,34 & 1.506 & 0,39 \\
\hline Total Geral & 5.677 & 1,60 & 7.047 & 1,84 \\
\hline
\end{tabular}

Fonte: DEE.

Anuário Estatístico do Brasil 1970. (IBGE).

Ao se analisar a distribuição dos leitos hospitalares segundo a finalidade (Tabela 7), constata-se que do total de leitos existentes no Estado, 64,5\% (4545 leitos) são gratuitos (não pagos ou previdenciários). Para o interior do Estado esta proporção é de $71,1 \%$ (2651 leitos) e para a capital é de 57,0\% (1894 leitos). A proporção de leitos gerais gratuitos para o Estado é de 64,0\% (2697 leitos) e de leitos especializados é de $65,3 \%$ (1848 leitos). Dos 2697 leitos gratuitos; 1046 $(38,8 \%)$ são de responsabilidade do poder público e os 1651 restantes estão sob o controle de entidades privadas. Dos 1046 leitos gratuitos, $470(45,5 \%)$ estão sob a responsabilidade do poder público estadual, $327(31,8 \%)$ do Federal, 204 (19,5\%) do Municipal e $45(3,2 \%)$ do Para-estatal. (Tabela 7).

Do total de leitos especializados os 1506 letios destinados à psiquiatria estão distribuídos em 4 hospitais que estão localizados em Fortaleza. Portanto, o interior do Estado não conta com nenhum hospital psiquiátrico. Os 682 leitos de lepra estão distribuídos em 2 hospitais localizados nos municípios de Maranguape e Redenção. Os 643 leitos destinados à tuberculose estão distribuídos em 3 hospitais localizados em Fortaleza, Maranguape e Sobral.

Em relação aos leitos especializados, $100 \%$ dos destinados à lepra (682 leitos) são gratuitos e de responsabilidade da esfera estadual. Do total de leitos destinados à tuberculose (643), 53,3\% são gratuitos sob a responsabilidade da esfera pública federal. Do total de leitos (1504) destinados à psiquiatria, 54,6\% (823) são gratuitos estando sob a respon- 
YUNES, J. - Situação da assistência médico-sanitária e hospitalar no Estado do Ceará. Brasil. Rev. Saúde puibl., S. Paulo, 7: 123-38, 1973.

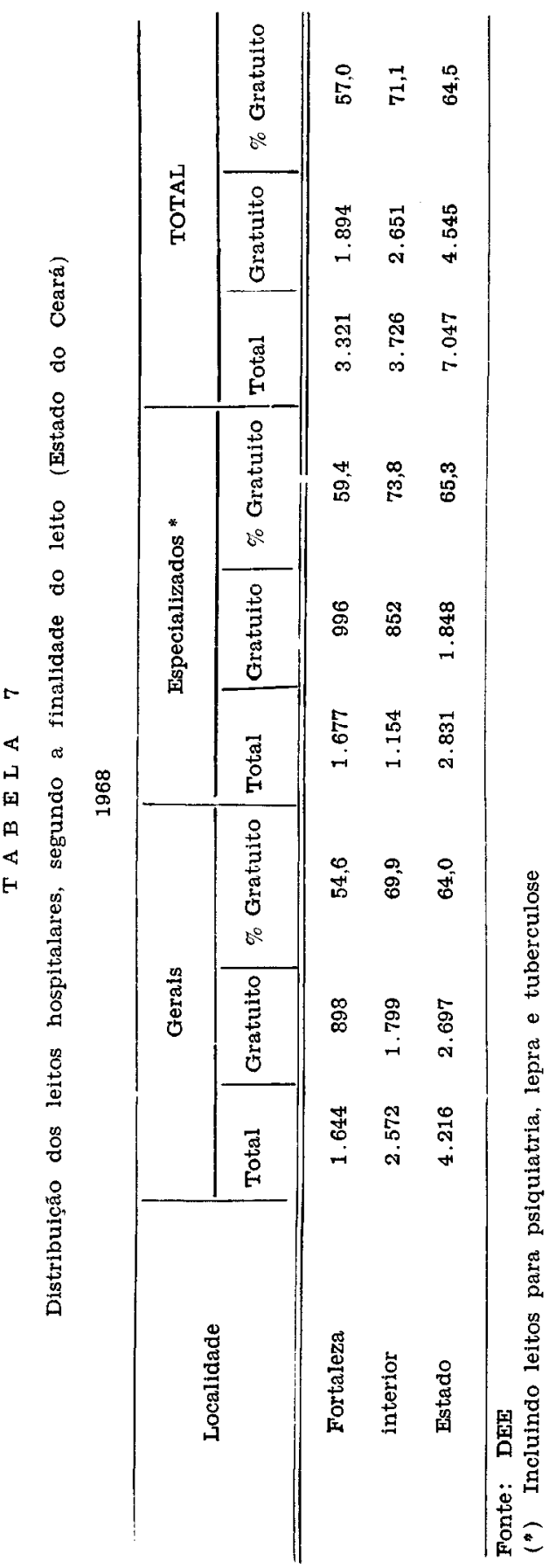

sabilidade da esfera pública estadual, 140 leitos e de entidades privadas, 683 .

Pelos dados analisados constata-se que a proporção de leitos considerados gratuitos é razoável, porém, a situação não pode ser considerada satisfatória, uma vez que se constatou que o número total de leitos e o seu coeficiente por mil habitantes é muito baixo, impedindo que uma boa parcela da população tenha acesso à assistência hospitalar, tanto geral como especializada.

A avaliação qualitativa da assistência hospitalar será feita indiretamente, através dos equipamentos considerados mais significativos para elaboração de diagnóstico, tais como, recursos laboratoriais, radiológicos e eletrocardiográficos, bem como, pelos recursos humanos existentes.

Do total de hospitais existentes no Estado (Tabela 8 ) somente $22,3 \%$ contam com reecursos laboratoriais para análises clínicas; 18,4\% para hematologia; $11,6 \%$ para bacteriologia; $9,7 \%$ para sorologia e 3,9\% para anatomia patológica. Quanto aos recursos de radiologia, somente $31,1 \%$ dos hospitais têm aparelhos de Raios $\mathrm{X}$ e em relação a eletrocardiografia somente $11,6 \%$ dos estabelecimentos têm aparelhos que permitem fazer eletrocardiograma. Nota-se portanto, que a maioria dos hospitais do Estado estão precariamente equipados, comprometendo o padrão qualitativo de atendimento médico. Constata-se que a maior carência destes recursos encontram-se nos estabelecimentos hospitalares do interior do Estado.

De acordo com a "Síntese do Relatório da Secretaria da Saúde" a situação atual dos hospitais mantidos pelo órgão é bastante constrangedora, quer quanto à conservação das instalações e equipamentos, bem como, à grande carência de recursos financeiros. Por exemplo, no se- 
YUNES, J. - Situação da assistência médico-sanitária e hospitalar no Estado do Ceará, Brasil. Rev. Saúde puibl., S. Paulo, 7: 123-38, 1973.

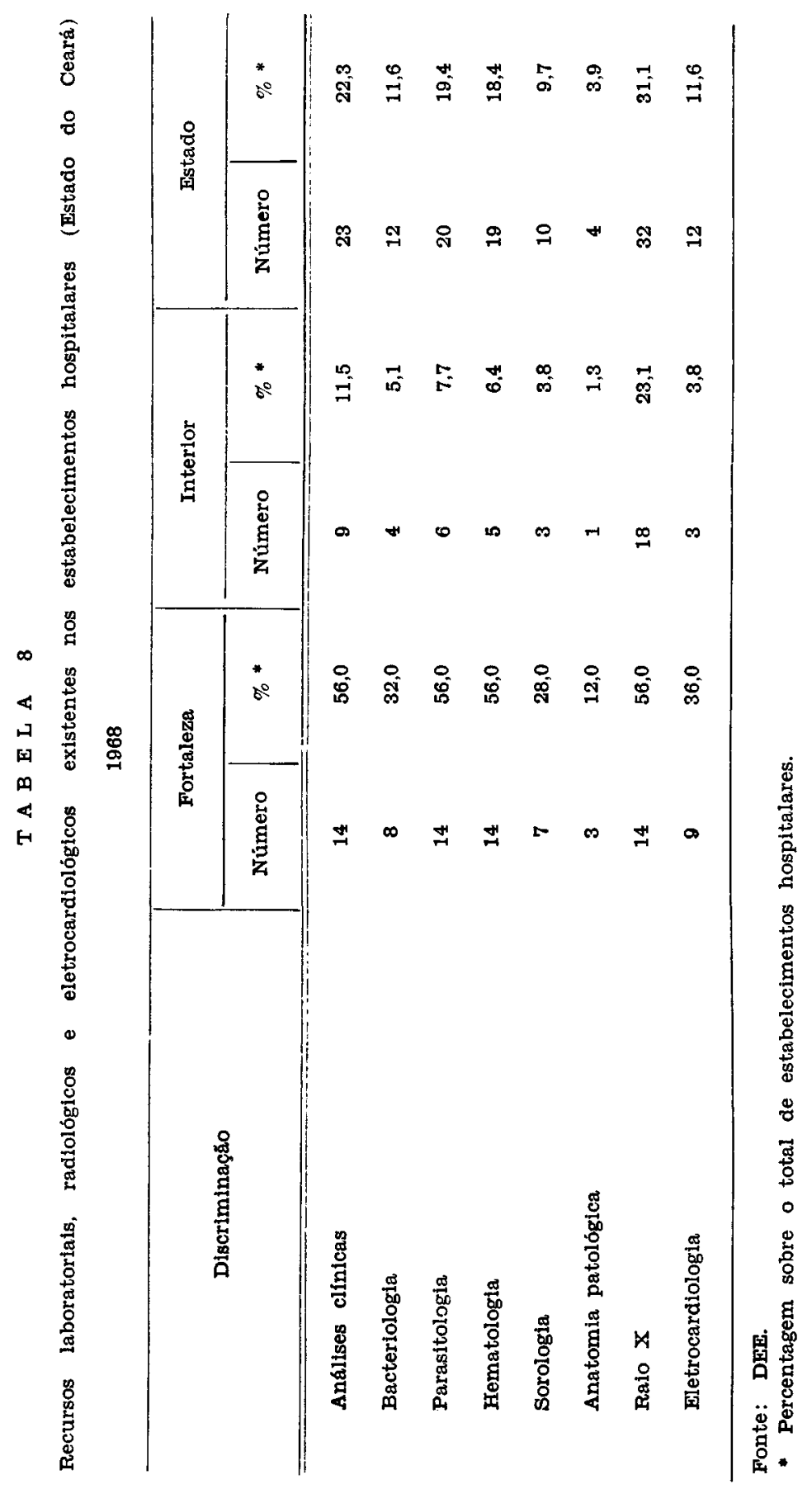


YUNES, J. - Situação da assistência médico-sanitária e hospitalar no Estado do Ceará Brasil. Rev. Saúde públ., S. Paulo, 7: 123-38, 1973.

tor de tuberculose por falta de recursos há impossibilidade de recuperação ou reequipamento dos aparelhos de Raios $\mathrm{X}$, bem como, aquisição de filmes, drogas e outros materiais que o tratamento do caso exige. O Hospital de Saúde Mental de Messejana projetado há mais de 20 anos, representava as necessidades daquela época. Atualmente a capacidade instalada e os precários recursos financeiros disponíveis são insuficientes para atenđer o aumento diário do número de doentes mentais que procuram esse nosocomio. As mesmas deficiências são constatadas nos hospitais de lepra do Estado do Ceará.

Em relação aos recursos humanos existentes, conforme Tabela 9, será analisada a proporção de estabelecimentos hos- pitalares que não contam com pessoal paramédico (pessoal auxiliar de saúde) e que indiretamente reflete na qualidade do serviço médico prestado. Com exceção do "profissional" atendente, mais de 50\% dos estabelecimentos hospitalares existentes no Estado do Ceará, conforme Tabela 9 , não contam com nenhum dos seguintes profissionais: enfermeiro, auxiliar de enfermagem, técnico de laboratório, auxiliar de laboratório, técnico operador de raios $\mathrm{X}$, auxiliar de raios $\mathrm{X}$, parteira prática, nutricionista e assistente social.

Esta situação define um dos estrangulamentos sérios da assistência médica prestada, pois o padrão qualitativo com a carência de recursos humanos constatada, encontra-se bastante comprometido.

T A B E LA 9

Estabelecimentos hospitalares sem pessoal paramédico, segundo o tipo (Estado do Ceará)

1968

\begin{tabular}{l|cc}
\hline \multicolumn{1}{r|}{ Pessoal paramédico por tipo } & Número & $\%$ \\
\hline Enfermeiro & 67 & 65,0 \\
$\begin{array}{l}\text { Auxiliar de enfermagem } \quad \text { (com certificado) } \\
\text { Prático de enfermagem }\end{array}$ & 56 & 54,4 \\
Assistente social & 73 & 70,9 \\
Nutricionista & 90 & 87,4 \\
Técnico de laboratório & 97 & 94,2 \\
Técnico operador raio $X$ & 78 & 75,7 \\
Auxiliar de raio $X$ & 79 & 76,7 \\
Atendente & 81 & 78,6 \\
Parteira prática & 21 & 20,4 \\
\hline
\end{tabular}

Fonte: DEE. 
YUNES, J. - Situação da assistêncla médico-sanitária e hospitalar no Estado do Cearâ, Brasil. Rev. Saúde públ., S. Paulo, 7: 123-38, 1973.

\subsubsection{1 - Municipios sem Atendimento Hospitalar}

Dos 141 municípios do Estado do Ceará, 89 , isto é, $62,7 \%$ não possuem nenhum hospital, fazendo com que cerca de 1.300.000 habitantes estejam teoricamente descobertos da assistência médica hospitalar (Tabela 10). A proporção de municípios por região sem hospitais é de mais de $50 \%$. Em ordem decrescente a proporção de municípios por região sem estabelecimentos hospitalares é de $73,3 \%$ para a 5. ${ }^{a}$ Região; 73,1\% (7.' Região); $63,6 \%$ (2.. Região); 53,3\% (6. ${ }^{a}$ Região) e $50,0 \%$ na $3 .^{a}$ Região. $O$ maior contingente populacional teoricamente descoberto de assistência médica hospitalar é da 1. ${ }^{a}$ Região com cerca de 270.000 habitantes.

$$
\text { T A B E L A } 10
$$

Municipios sem atendimento hospitalar, por regióes (Estado do Ceará)

1968

\begin{tabular}{|c|c|c|c|c|}
\hline \multirow{2}{*}{ Regiōes } & \multirow{2}{*}{$\begin{array}{l}\text { Número de } \\
\text { Municípios }\end{array}$} & \multicolumn{2}{|c|}{$\begin{array}{l}\text { Municípios sem Uni. } \\
\text { dades Hospitalares }\end{array}$} & \multirow{2}{*}{$\begin{array}{l}\text { População sem } \\
\text { Atendimento }\end{array}$} \\
\hline & & Número & $\%$ & \\
\hline $1 .^{\mathrm{a}}$ & 27 & 16 & 59,2 & 270.063 \\
\hline $2 .{ }^{a}$ & 33 & 21 & 63,6 & 246.204 \\
\hline $3 .^{a}$ & 10 & 5 & 50,0 & 99.732 \\
\hline $4 .^{a}$ & 16 & 9 & 56,2 & 111.226 \\
\hline $5 . .^{a}$ & 15 & 11 & 78,6 & 217.161 \\
\hline $6 .^{a}$ & 15 & 8 & 53,3 & 80.342 \\
\hline $7 .^{\mathrm{a}}$ & 26 & 19 & 73,1 & 256.643 \\
\hline TOTAL & 141 & 89 & 62,7 & 1.281 .371 \\
\hline
\end{tabular}

Fonte: DEE.

Anuário Estatístico do Brasil 1970 (IBGE).

\subsection{2 - Rede Para-Hospitalar}

No Estado do Ceará, conforme Tabela 11, existem 86 unidades para-hospitalares, sendo 54 representadas por Postos de Puericultura sob responsabilidade da Legião Brasileira de Assistência; 2 prontosocorros isolados (não anexos a hospital) um sob responsabilidade do Instituto Nacional de Previdência Social (INPS) localizado em Juazeiro e um pertencente a entidade privada, instalado em Fortaleza. As 30 unidades para-hospi- talares restantes são representadas por ambulatórios gerais e especializados sob responsabilidade predominante de entidade privadas, porém dela também participam as entidades públicas estadual, municipal, federal e para-estatal.

Em relação aos equipamentos laboratoriais existentes que medem indiretamente o padrão qualitativo de atendimento, do total de 86 estabelecimentos para-hospitalares existentes, somente 3 unidades contam com recursos para rea- 
YUNES, J. - Situação da assistência médico-sanitária e hospitalar no Estado do Ceará. Brasil. Rev. Saüde públ., S. Pauío, 7: 123-38, 1973.

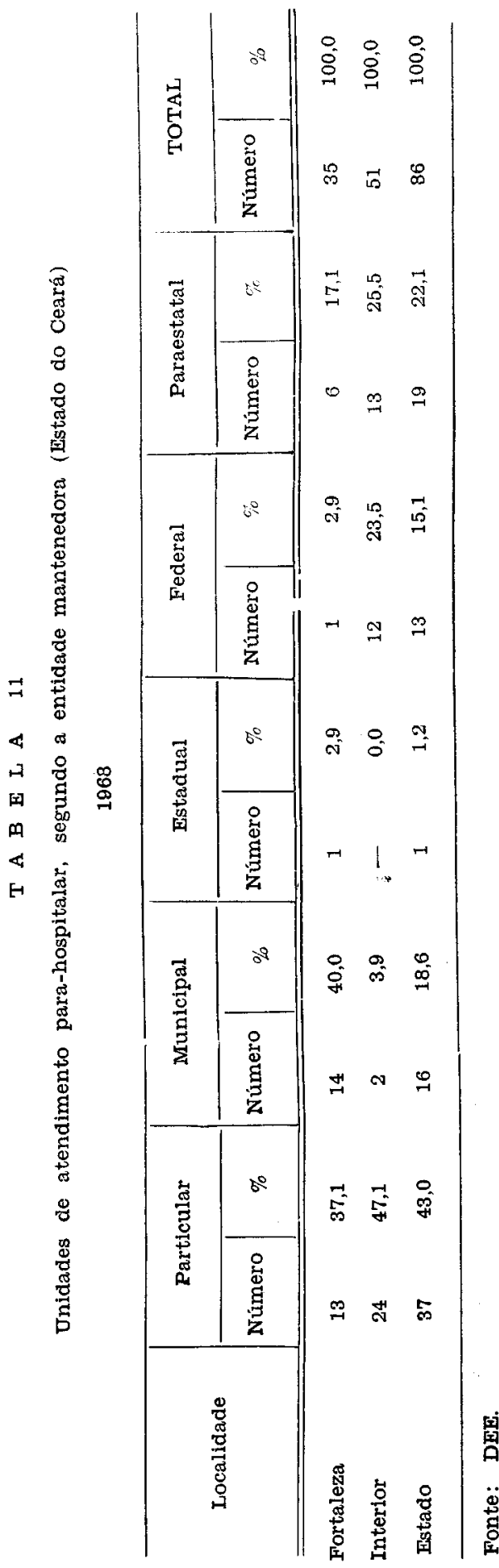

lização de análises clínicas, uma para bacteriologia, uma para parasitologia e uma para hematologia e sorologia.

No Estado do Ceará, 25 municipios $(17,61 \%)$ não contam com nenhuma unidade sanitária ou recursos hospitalares e para-hospitalares, fazendo com que cerca de 233.000 habitantes estejam teoricamente descobertos de qualquer tipo de assistência médica.

A carência de dados deste setor é maior do que outros já analisados o que impede um aprofundamento mais pormenorizado em seu diagnóstico. Porém, os dados existentes permitem afirmar que tanto quantitativamente como qualitativamente o padrão de atendimento está deficitário.

\section{3 - Pessoal Médico e Paramédico}

A avaliação dos recursos médicos e paramédicos no Estado do Ceará fez-se através do número de médicos e dentistas existentes no Estado e do pessoal paramédico lotado na Secretaria da Saúde do Estado e nos Estabelecimentos Hospitalares.

No Estado do Ceará, de acordo com a Tabela 12, existem 1207 médicos que proporcionam a relação de somente 0,3 médicos por mil habitantes, quando o padrão teoricamente recomendado é de no mínimo 1 médico/1000 habitantes. Além do número de médicos ser insuficiente, há uma má distribuição deste profissional, uma vez que $938(77,7 \%)$ estão concentrados na Capital do Estado com um coeficiente de 1,1 médico/ 1000 habitantes. $O$ interior do Estado conta apenas com 269 profissionais e um coeficiente reduzido de 0,07 médicos/1000 habitantes.

Dos 141 municípios que compõem o Estado do Ceará, $40(28,4 \%)$ não possuem médico e $37(26,2 \%)$ contam com este 
YUNES, J. - Situação da assistência médico-sanitária e hospitalar no Estado đo Ceará Brasil. Rev. Saúde públ., S. Paulo, 7: 123-38, 1973.

T A B E L A 12

Assistência médica - odontológica (Estado do Ceará)

1970

\begin{tabular}{|c|c|c|c|c|c|}
\hline \multirow{2}{*}{ Localidade } & \multirow{2}{*}{ Habitantes } & \multicolumn{2}{|r|}{ Médicos } & \multicolumn{2}{|r|}{ Dentistas } \\
\hline & & N. ${ }^{\circ}$ & Coeficiente $*$ & N. ${ }^{\circ}$ & Coeficiente $* *$ \\
\hline Fortaleza & 842.231 & 938 & 1,1 & - & - \\
\hline Interior & 3.598 .145 & 269 & 0,07 & - & - \\
\hline Estado & 4.440 .376 & 1207 & 0,3 & 599 & 0,28 \\
\hline
\end{tabular}

Fonte: Centro Médico Cearense e Conselho Regional de Odontologia

* por 1000 habitantes

* * por 2000 habitantes

profissional, porém não residem no município em que trabalham, portanto, o pessoal médico disponivel não é permanente. Somente $64(45,4 \%)$ dos municípios do Estado do Ceará contam com médicos residentes. As regiões que apresentam a maior proporção de municípios sem médicos são em ordem decrescente de grandeza, as seguintes: 7. ${ }^{\mathrm{a}}$ Região $(38,5 \%), 1 .^{\mathrm{a}}$ Região $(33,3 \%), 6 .^{\mathrm{a}}$ Região $(33,3 \%), 4^{2}$ Região $(25,0 \%), 2^{2}$ Região $(24,2 \%), 5$. $^{\text {R Região }}(21,4 \%)$ e $3 .^{\text {a }}$ Região $(10,0 \%)$ (Tabela 13 ).

T A B E L A 13

Distribuições dos municípios, por regióes segundo o pessoal médico existente (Estado do Ceará)

1970

\begin{tabular}{|c|c|c|c|c|c|c|c|c|}
\hline \multirow{2}{*}{ Regiốes } & \multicolumn{2}{|c|}{ Municípios } & \multicolumn{2}{|c|}{ Médico Residente } & \multicolumn{2}{|c|}{ Médico N/Residente } & \multicolumn{2}{|c|}{ Sem Médico } \\
\hline & Número & $\%$ & Número & $\%$ & Número & $\%$ & Número & $\%$ \\
\hline $1 .{ }^{\mathrm{a}}$ & 27 & 100.0 & 8 & 29,6 & 10 & 37,1 & 9 & 33,3 \\
\hline $2 .^{a}$ & 33 & 100,0 & 15 & 45,5 & 10 & 30,3 & 8 & 24,2 \\
\hline 3.2 & 10 & 100,0 & 6 & 60,0 & 3 & 30,0 & 1 & 10,0 \\
\hline $4 . .^{\mathrm{a}}$ & 16 & 100,0 & 7 & 43,8 & 5 & 31,2 & 4 & 25,0 \\
\hline 5.2 & 14 & 100,0 & 7 & 50,0 & 4 & 28,6 & 3 & 21,4 \\
\hline $6 .^{a}$ & 15 & 100,0 & 7 & 46,7 & 3 & 20,0 & 5 & 33,3 \\
\hline $7 .^{\mathrm{a}}$ & 26 & 100,0 & 14 & 53,8 & 2 & 7,7 & 10 & 38.5 \\
\hline TOTAL & 141 & 100,0 & 64 & 45,4 & 37 & 26,2 & 40 & 28,4 \\
\hline
\end{tabular}

Fonte: Serviço de Saúde do Interior (DES). DNERu.

FSESP. 
YUNES, J. - Situação da assistência médico-sanitária e hospitalar no Estado do Ceará Brasil. Rev. Saúde públ., S. Paulo, 7: 123-38, 1973.

Em relação ao número de dentistas, existem para todo o Estado 599 profissionais que proporcionam um baixo padrão quantitativo de 1,4 dentistas/2000 habitantes, quando o padrão geralmente aceito é de um dentista/2000 habitantes. Esta carência é homogênea para todas as Regiōes do Estado.

Em relação ao pessoal paramédico a carência é ainda maior. Do pessoal lotado na Secretaria da Saúde do Estado o número de enfermeiras, nutricionistas, parteiras e de nível médio (auxiliar de enfermagem, laboratorista, operador de Raios X e outros) é bastante reduzido, predominando no serviço de enfermagem o profissional do tipo atendente.

Quanto ao pessoal lotado nos estabelecimentos hospitalares já foi constatado quando da análise da rede hospitalar, que mais de $50 \%$ destas unidades não possuem pessoal paramédico qualificado.
Conclui-se, portanto, que os recursos médicos e paramédicos existentes não correspondem à relação do pessoal desejável, afetando dessa maneira, a qualidade do atendimento dos serviços de saúde, bem como, impossibilitando que uma boa parcela da população tenha acesso à assistência médica.

\section{CONCLUSOES}

1. O conhecimento do sistema de proteção e recuperação da saúde é etapa fundamental para a sua programação, principalmente quando esta deve fazer parte de um plano integral de desenvolvimento.

2. O baixo padrão quantitativo e qualitativo da assistência médica en. contrado tende a se deteriorar se a expansão dos recursos não acompanhar o crescimento populacional.

RSPU-B/166

Yunes, J. - [Medical care situation in the State of Ceara, Brazil]. Rev. Saúde públ., S. Paulo, 7:123-38, 1973.

Summary: The situation of medical care in the State of Ceara (Brazil) was estimated through the analysis of the offering of the official services on public health, hospital and "para-hospital" care and by the existent human resources as well. This region has 141 towns and aproximately 4,000.000 inhabitants. The official services on Public Health are concerned to State public expense in $59.6 \%$ of the sanitary units; Federal government gives its participation in $26.9 \%$ and the city council helps in $13.5 \%$. The quantitative standard observed was considered as been satisfactory, since as a rule there is one sanitary unit per each 23,002 inhabitants. This average is very near to the required one unit per each 50,000 inhabitants. The qualitative appreciation, considered indirectly through the actual laboratory and human resources, seemed to be inefficient since only $16.7 \%$ of the health units have laboratory and 12.3\% have no physicians; 21.7 (39) of the health center are closed because of the lack of this kind of professional related above. Paralel to this situation one can detect the existance of equipments completely out of date and the nearly absolute defficiency in the section of drug supply. From the 141 towns which compose the Region of Ceara, 31 (22\%) have no health unit and in $25(17.7 \%)$ we don't find any health resource. In the first presented case the population of medical care theoretically found out is of 378,449 inhabitants and in the second case it is of 232,900 inhabitants. From the 103 actual hospitals in this present Region $77.7 \%$ is on the responsability 
YUNES, J. - Situação da assistência médico-sanitária e hospitalar no Estado do Ceará, Brasil. Rev. Saúde pübl., S. Paulo, 7: 123-38, 1973.

of the private section and $25 \%$ is concentrated in the capital of the Region. The quantitative standard of 1.84 beds 1000 inhabitants (7047 beds) is extremely low when compared with the Brazilian average of 3.6 beds. The theoretically recomended average is 4.5 (beds). From the total number of beds $1.10 / 1000$ are considered general and $0.74 / 1000$ are specialized (tuberculosis, leprosy and psychiatry). The qualitative stantard of the hospital attendance is implicated since only $22.3 \%$ of the foundation have laboratory; $31.1 \%$ have $X$ Ray apparatus and $11.6 \%$ present electro-cardiography. The most proeminent shortage of these resources occur in the countryside of this Region. More than $50.0 \%$ of the hospitals have no professional on health section, such us nursery, nutritionist, social work and technicians. From the 141 towns, $62.7 \%$ (89) have no hospitals, consequently about 1,300.000 inhabitants are theoretically in need of hospital care. Related to the 86 para-hospital units, through the lack of data is bigger, the situation is rather similar to the hospital care. There are 1207 physicians in the Region who offer a patterns of 0.3 physicians 1000 inhabitants when the recomended patern theorically is an average 1/1000. In spite of being a rather insignificant rate there is an unfair distribuition of physicians for $77.7 \%$ of these workers are concentrated in the capital of the Region (1.1/1000 inhabitants). Only $45.4 \%$ of the cities have resident physician, related to dentistry field one can observe a low quantitative pattern of 0,28 workers per 2.000 inhabitants when the generally acceptable amount is of $1 / 2000$ inhabitants. Concerning with the para-medical workers there is a predominance of medical attendants in the Official Services of Public Heath and as it has already been mencioned above more than $50.0 \%$ have no qualified workers in the hospitals.

UnITERms: Medical care (Ceara, Brazil)*; Hospitals (Ceara, Brazil)*; Public health services*. 